\title{
Penoscrotal three-piece inflatable penile prosthesis placement: surgical technique
}

\author{
Matthew J. Watson, Anand Shridharani \\ Department of Urology, University of Tennessee-Chattanooga, Chattanooga, TN, USA \\ Correspondence to: Anand Shridharani. Department of Urology, University of Tennessee-Chattanooga, Chattanooga, TN, USA. \\ Email: anand.shridharani@gmail.com.
}

Received: 06 April 2019; Accepted: 11 November 2019; Published: 05 July 2020.

doi: 10.21037/jovs.2019.11.09

View this article at: http://dx.doi.org/10.21037/jovs.2019.11.09

\section{Introduction}

The development of the inflatable penile prosthesis (IPP) in 1973 changed the landscape of erectile dysfunction (ED) management. It is the first and only treatment to prove efficacious in all males while simulating an erect and flaccid state. Subsequent developments in the device, such as new cylinder designs to prevent aneurysm, antibiotic coatings to reduce infection and lockout valves to prevent autoinflation, have caused the device to be widely accepted and utilized. Now IPPs more closely approximate natural flaccidity, natural erection and are much more reliable. The penoscrotal approach to IPP placement is most common approach utilized and performed in over $80 \%$ of the IPPs placed (1). Although the penoscrotal approach does not allow direct visualization of the reservoir placement, it likely derives its popularity due to the excellent corporal exposure allowed, even in the obese patients (Table 1). Herein, we describe the surgical technique to IPP placement using a penoscrotal approach.

\section{Indications and preoperative counseling}

Penile implants are used in patients who have failed nonsurgical therapies for ED such as phosphodiesterase 5 inhibitors, vacuum erectile devices and intracavernosal injections. Additionally, IPPs are also used in patients who cannot tolerate non-surgical management or those who are not candidates for nonsurgical management. The preoperative discussion and informed consent process should be directed at both the men and their partners. While patient and partner satisfaction have been shown
Table 1 Penoscrotal IPP attributes

\begin{tabular}{l} 
Advantages of penoscrotal IPP placement \\
Optimal corporal exposure \\
Minimal risk of dorsal nerve injury \\
Optimal approach in severely obese \\
Anchoring of pump directly in scrotum \\
Optimal approach in patients with severe corporal fibrosis \\
Minimal scar \\
Can perform concomitant scrotoplasy, AUS placement, Mini- \\
Jupette (sling) through same incision \\
Disadvantages of penoscrotal IPP placement \\
Blind placement of reservoir \\
Increased scrotal swelling \\
\hline IPP, inflatable penile prosthesis.
\end{tabular}

to both be upwards of $95 \%$, this discussion provides a framework to discuss post-operative penile length, appearance, sensation and sexual function (2). An in-depth discussion regarding each aspect helps manage patient expectations and mitigate risk (3).

There are only three absolute contraindications to device placement that are listed by the implant manufacturers. Patients with active infections, especially those in the genitourinary tract or the genital skin should not receive an implant due to the increased risk of IPP infection necessitating device explantation. A relative contraindication would include a patient without the dexterity or mental capacity to inflate or deflate the device. 


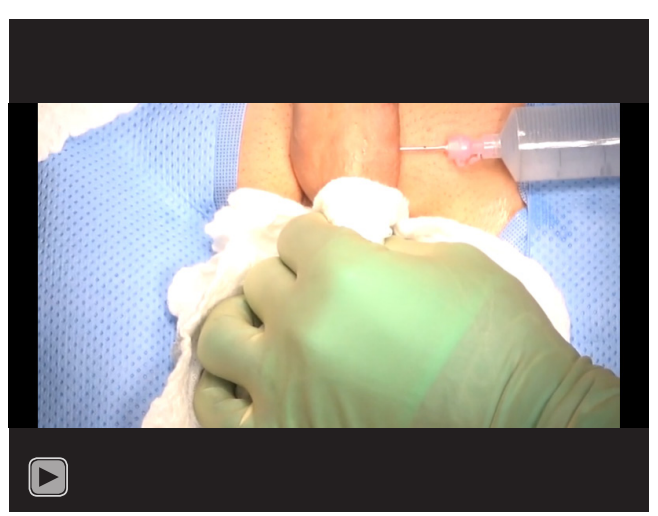

Video 1 Artificial erection and exposure (4).

\section{Positioning, preparation and draping}

We provide antibiotic surgical prophylaxis in the form of IV Vancomycin and Gentamicin. Patients usually void prior to entry in to the operating room to decrease the need of preimplantation catheterization. The patient is laid supine on the operating table and anesthesia is induced. Hair is carefully removed from the scrotum, penis and suprapubic area using a sterile clipper or razor. Chlorhexidine scrub followed by a ChloraPrep paint is used to prep the skin from the anterior midthigh superiorly to the umbilicus. The surgeon usually applies the final ChloraPrep preparation. Prior to draping, the prep should be allowed to dry.

Using sterile blue lint-free towels, we drape out the field leaving the lower abdomen, penis and scrotum exposed. A laparotomy drape with the small opening centered over the penis and scrotum. The patient is placed in slight trendelenburg position to level the penis and scrotum, as this helps especially with men with increased suprapubic fat or abdominal obesity. A Foley catheter may be placed at this time depending on surgeon preference. Some surgeons choose to leave the urethral catheter in place throughout the duration of the procedure to aid in the identification of the urethra by palpation. We routinely do not; however, we recommend continual catheter placement in men with corporal fibrosis, men undergoing penile implant replacement or those with altered anatomy to reduce the risk of urethral injury.

\section{Retraction and exposure (see video-artificial erection and exposure) (Video 1)}

The patient receives a dorsal penile nerve block, and the proximal corporal are infiltrated with anesthetic along the

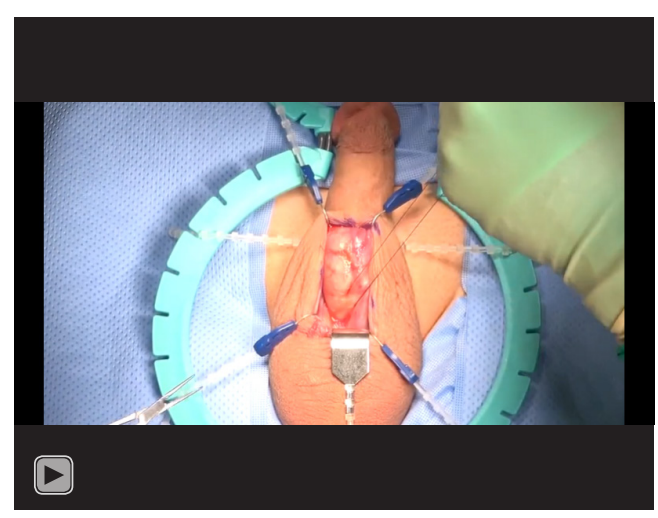

Video 2 Corporotomy and measurement (5).

inferior pubic rami. A saline, papaverine and ropivacaine mixture is injected into the proximal corpora cavernosum bilaterally in order to induce an artificial erection. Inducing an artificial erection aids in pre-dilating the corpora and identifying any Peyronie's disease. A penoscrotal incision is made longitudinally through the penile/scrotal raphe.

Maximal corporal and urethral exposure are hallmarks of the penoscrotal approach. To gain appropriate visualization of these structures either blunt dissection with finger sweep or sharp dissection of the dartos tissue can be performed. Once the urethra is in the midline with paired corpora are visualized alongside it, a Wilson-Scott retractor may be placed. Some implanters are comfortable without stationary retractors and use the corporotomy sutures for retraction.

\section{Corporotomy and dilation (see video- corporotomy and measurement) (Video 2)}

Stay sutures are placed into the corpus cavernosum on either side of the site of the future corporotomies using a 2-0 absorbable monofilament. These stay sutures help facilitate subsequent placement of the implant cylinders and to aid in closing the corporotomies at the end of the procedure. Each corporotomy is made longitudinally with a 15 -blade or electrocautery, between the stay stitches, to expose the intracavernosal smooth muscle. The length of this incision should be the shortest length necessary for insertion of the implant, which in most cases is $1.5 \mathrm{~cm}$.

Once the corporal bodies are opened, a space for the cylinders is made either by deliberate corporal dilation or by using a Furlow device. The purpose of dilation is to create a space for the cylinders and facilitates obtaining maximal corporal dimensions. Proximal corporal dilation 


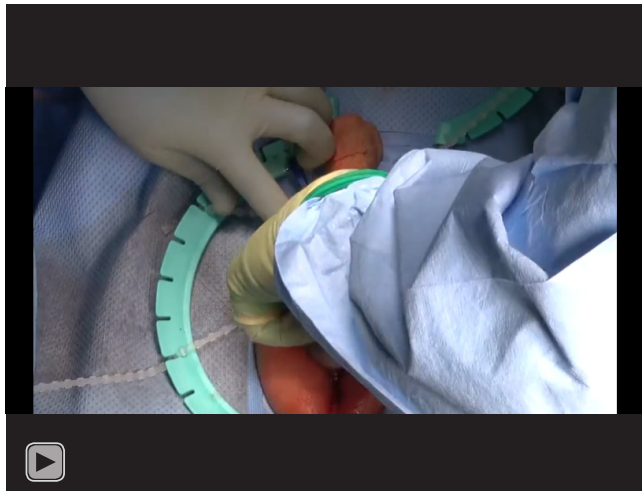

Video 3 Reservoir placement (8).

may be performed with either the Yankauer suction tip or serial dilation with metal dilators. The dilation should be carried until the dilating device hits a firm stop at the inferior pubic ramus. When dilating the proximal corpora, the penile shaft should be placed on stretch and angled to the contralateral side of the corpora being dilated. This helps place the corpora in a straight line and minimizes the chance of corporal crossover. If crossover is suspected, Brooks dilators can be placed into each proximal corpora in order to perform the "field-goal test" to check for crossover. Additionally, if no firm stop of dilator is noted, and/or the dilator tract is felt to travel medial to the ramus, proximal perforation should be suspected. At this point, strong consideration should be given to placing a rear-tip sling, which has been described in detail elsewhere (6).

Distal dilation is begun with closed Metzenbaum scissors and is best performed where pressure is applied in a smooth, controlled fashion. The tips of the scissors are aimed towards the dorsolateral aspect of the respective corpora. Dorsolateral positioning helps prevent distal crossover and urethral injury as these occur with medial and ventromedial trajectories, respectively. Additionally, compressing the urethra and manipulating it away from the tip of the dilating instrument may aid in preventing urethral perforation. If urethral injury is suspected, forceful injection of saline through the corporotomy with a bulb syringe is performed observing for meatal expulsion of irrigant.

Following dilation, the Furlow measuring tool is used to measure the corporal length. The proximal and distal dimensions are measure to a fixed point. We prefer the corporotomy suture as we feel that measurement to the respective edge of the corporotomy will undersize corporal length. It is important that the Furlow be palpated on the dorsolateral aspect of the glans to maximize length measurement. Once the proximal and distal dimensions are added together, there should be no more than a one $\mathrm{cm}$ discrepancy between the two sides. Cylinder size and rear tip extender length is ascertained. As a general rule, rear tip length should be minimized and less than $3 \mathrm{~cm}$ total; however, sometimes rear-tips are used to maintain tubing length to allow dependent positioning of the implant pump. In these situations, consideration should be made to lengthening the corporotomy proximally. This increases the effective tubing length outside of the corpora and may reduce the length of rear tip extender needed.

\section{Device preparation}

The implant is prepared on a mayo stand which is designated only for device component preparation. Gloves should be changed and new to prevent any exposure of the implant to bacteria. Reservoir preparation occurs first and usually is performed prior to incision. Cylinder/ pump preparation differs with regards to inflatable implant manufacturer. The Boston Scientific devices are impregnated with Inhibizone and do not require any antibiotic solution for dipping. The Coloplast Titan has a hydrophilic coating that absorbs and binds any aqueous solution. Antibiotic dip can be adjusted to regional, or hospital recommendations; however, we routinely use Rifampin with the addition of Amphotericin B in diabetic patients since the population has a higher risk of fungal infection (7). Historically, the penoscrotal approach has a low infection rate.

The device should be inflated and completed deflated on the back table prior to insertion to confirm function and remove air from the system. Forceful instillation of saline though the reservoir tubing will activate and prime the pump mechanism. Additionally, this may prevent future "sticky" pump.

\section{Reservoir placement (see video-reservoir placement) (Video 3)}

There are multiple sites to place a reservoir including the classic Space of Retzius position just posterior to the pubis or in an ectopic position, which encompasses multiple different positions outside or adjacent to the posterior pubis position. The bladder should be decompressed prior to reservoir placement. We routinely gain access into Retzius' space bluntly via the external inguinal ring. A finger is 


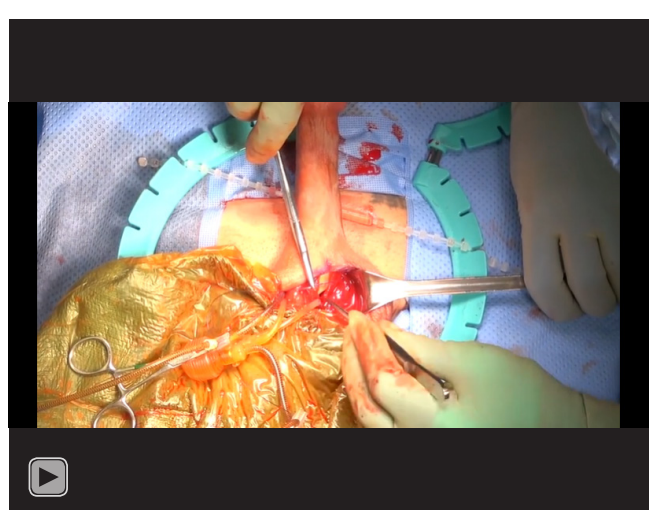

Video 4 Cylinder placement, and corporotomy closure (9).

placed on the ring then directed medial and inferior. The correct position is confirmed by feeling the smooth posterior aspect of the superior ramus of the pubic bone. Access to an ectopic position, either submuscular or deep to transversalis fascia, is aided with the use of a long nosed nasal speculum via the roof of the inguinal ring or floor of the ring, respectively. All of these potential reservoir sites should be entered bluntly to minimize potential injury to the bladder, bowel or iliac vessels. If these spaces cannot be entered easily, strong consideration should be given to making a counter incision to place the reservoir under direct vision.

Prior to reservoir placement, gloves are changed and the exposed skin is covered by blue towels to minimize the chance of skin touching the implant. The implant is placed within its respective position with the use of the Yankauer suction tip. The reservoir is then filled with saline to an appropriate amount above the cylinder capacity. Back pressure after filling should not be present. Confirm correct placement, redevelop the space or choose another if significant back pressure is identified.

\section{Cylinder sizing and placement (see video- cylinder placement, and corporotomy closure) (Video 4)}

After the reservoir is placed, gloves are changed again, and Ioban covered towels are brought onto the field and placed just inferior to the field covering the scrotal skin. The implant is properly oriented on this Ioban surface. The cylinder sutures are loaded into the Furlow. The Furlow is placed into the distal corpora, with the needle pointing towards the glans, and the Furlow is advanced.

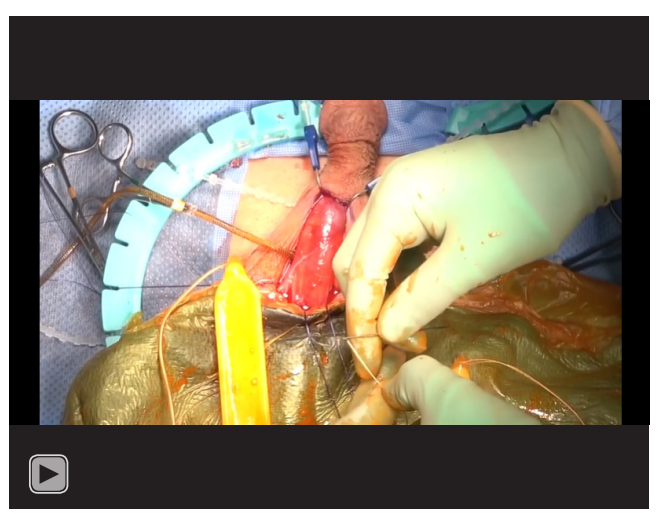

Video 5 Pump placement (13).

Dorsolateral pressure is applied to the corpora by the Furlow once resistance is met and the glans and urethra are rotated away from the tip of the Furlow. The cylinder is then passed distally into the corpora. Care is taken not to allow the implant to touch the skin during placement. Tension is applied to the cylinder string and rotated away from the corporotomy. This allows optimal exposure of the corporotomy for proximal cylinder placement. If concern for corporal crossover exists, a dilator should be left in place in the contralateral proximal corpora during placement. After the cylinder is appropriately placed without signs of kinking, the process is repeated on the other side. Rapid inflation is then performed to ensure adequate positioning of the implant. Multiple maneuvers for curvature, Peyronie's disease, floppy glans, or malpositioned cylinders may be performed at this point and are described elsewhere (10-12).

Corporotomy closure is performed by running an absorbable monofilament. The stay sutures may be used to close them as well. We usually run the corporal closure as most of the postoperative hematoma formation associated with implant placement is likely from a corporal source. Nevertheless, there exists the potential to damage the implant with a running corporal closure and should be pursued with caution.

\section{Pump placement, tubing connections and drain placement (see video_pump placement) (Video 5)}

A subdartos pouch is created for the pump within the scrotum using a nasal speculum to open the space posteriorly in the wound. Accessing this space bluntly usually minimizes the risk of postoperative hematoma formation. Pump positioning, anterior versus posterior, 


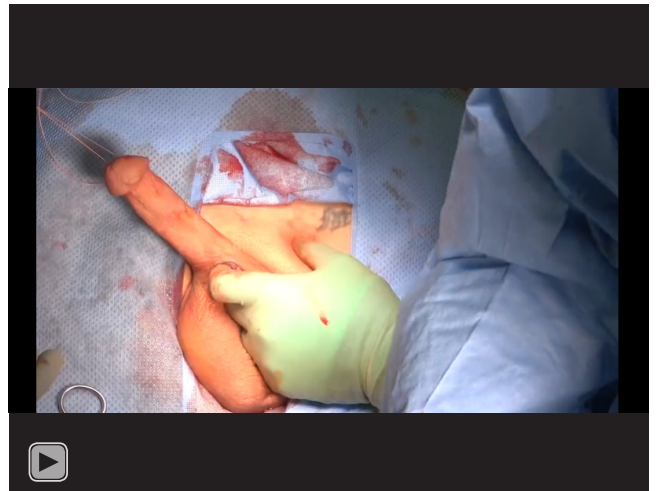

Video 6 Drain placement (15).

should be individualized to the patient and we often ask patient preference prior to implantation. With the pump in place, the cylinders, pump and reservoir tubing are connected. The device is re-inflated to confirm proper function.

A 10-French Blake closed system suction drain within the area of corporotomies and pump is placed. The drain exits the pubis on the contralateral side as the pump and reservoir and is sewn in place on the skin with a 3-0 nylon. We believe a drain, combined with scrotal compression, helps reduce rate of postoperative hematoma formation and decreased narcotic usage. In our practice, closed system drainage is routinely continued for three days. Usually implanters will leave no drain or a drain for 24 hours. Closed system drains have not led any increased rate of infection in contemporary literature (14).

\section{Closure, dressing and post-operative care (see video-drain placement) (Video 6)}

Closure of the tissue is done in multiple layers and care is taken not to incorporate the tubing or drain, or damage the implant components. Skin is closed with a 4-0 Monocryl in a subcuticular fashion, then dressed with Dermabond. The implant is partially inflated and the bladder is emptied via catheterization and the Foley is removed. A "mummy wrap" is created around the penis and scrotum using a Conform gauze wrap and Coban self-adherent wrap to decrease swelling. It is important to wrap the penis loosely so that the urethra is not compressed when swelling occurs, as this may cause urinary difficulty or glans ischemia in rare instances (16). The cylinder sutures are then removed. The exit sites are pinched and dressed with Dermabond. Fluffs and supportive jockstrap are also placed on the patient. Patients are discharged home with three-day follow-up for drain removal. They are given oral antibiotics for three days until drain removal, and a prescription for oral narcotics that would last them 72 hours. They follow up in clinic on post-operative day three for wound check and drain removal. The patient begins cycling device at two to three weeks postoperatively, depending on patient comfort. The patient is able to use the device for sexual activity at four to six weeks postoperatively.

\section{Role of team members}

The importance of the multiple members of the implant team working in unison cannot be overstated. In our institution, the coordinated efforts of all team members ensure that each step is carried out both effectively and efficiently. This includes preoperative and post anesthesia care unit nurses who provide patient instructions, answer questions and direct the workflow prior to and after the operating room. A scrub nurse provides appropriate instruments and prepares the implant. The circulating nurse scrubs the patient and maintains a smooth workflow throughout all phases of the operation, including coordination with the pre-operative and post-operative care area personnel. Additionally, the anesthesiologists and anesthetists monitor the airway and stability of the patient during the procedure. Finally, the resident or assistant is responsible for draping the patient, assistance during the operation, wound dressing and postoperative care implementation.

\section{Conclusions}

The penoscrotal approach is an excellent technique for IPP placement. This technique can be employed for most patients and provides excellent corporal exposure. With careful patient selection and preoperative counseling, both patient and surgeon satisfaction are very high using this approach.

\section{Acknowledgments}

Funding: None.

\section{Footnote}

Provenance and Peer Review: This article was commissioned by the Guest Editors (Martin Gross, Jay Simhan and Faysal 
A. Yafi) for the series "Penile Prosthesis Surgery" published in Fournal of Visualized Surgery. The article did not undergo external peer review.

Conflicts of Interest: Both authors have completed the ICMJE uniform disclosure form (available at https://jovs. amegroups.com/article/view/10.21037/jovs.2019.11.09/ coif). The series "Penile Prosthesis Surgery" was commissioned by the editorial office without any funding or sponsorship. AS reports personal fees (Consulting) from Coloplast, Inc, personal fees (Consulting) from Endo Pharmaceuticals, outside the submitted work. The authors have no other conflicts of interest to declare.

Ethical Statement: The authors are accountable for all aspects of the work in ensuring that questions related to the accuracy or integrity of any part of the work are appropriately investigated and resolved. All procedures performed in this study were in accordance with the Helsinki Declaration (as revised in 2013). The manuscript is waived from patient informed consent according to the ethics committee or institutional review board.

Open Access Statement: This is an Open Access article distributed in accordance with the Creative Commons Attribution-NonCommercial-NoDerivs 4.0 International License (CC BY-NC-ND 4.0), which permits the noncommercial replication and distribution of the article with the strict proviso that no changes or edits are made and the original work is properly cited (including links to both the formal publication through the relevant DOI and the license). See: https://creativecommons.org/licenses/by-nc-nd/4.0/.

\section{References}

1. Henry GD, Karpman E, Brant W, et al. The Who, How and What of Real-World Penile Implantation in 2015: The PROPPER Registry Baseline Data. J Urol 2016;195:427-33.

2. Montorsi F, Rigatti P, Carmignani G, et al. AMS threepiece inflatable implants for erectile dysfunction: a longterm multi-institutional study in 200 consecutive patients. Eur Urol 2000;37:50-5.

3. Trost LW, Baum N, Hellstrom WJ. Managing the difficult penile prosthesis patient. J Sex Med
2013;10:893-906; quiz 907.

4. Watson MJ, Shridharani A. Artificial erection and exposure. Asvide 2019;6:080. Available online: http://www. asvide.com/watch/33120

5. Watson MJ, Shridharani A. Corporotomy and measurement. Asvide 2019;6:081. Available online: http:// www.asvide.com/watch/33121

6. Wilson SK. Rear tip extender sling: a quick and easy repair for crural perforation. J Sex Med 2010;7:1052-5.

7. Gross MS, Phillips EA, Carrasquillo RJ, et al. Multicenter Investigation of the Micro-Organisms Involved in Penile Prosthesis Infection: An Analysis of the Efficacy of the AUA and EAU Guidelines for Penile Prosthesis Prophylaxis. J Sex Med 2017;14:455-63.

8. Watson MJ, Shridharani A. Reservoir placement. Asvide 2019;6:082. Available online: http://www.asvide.com/ watch/33122

9. Watson MJ, Shridharani A. Cylinder placement, and corporotomy closure. Asvide 2019;6:083. Available online: http://www.asvide.com/watch/33123

10. Bickell M, Manimala N, Parker J, et al. Floppy Glans Syndrome: Pathogenesis and Treatment. Sex Med Rev 2016;4:149-56.

11. Mulhall J, Anderson M, Parker M. A surgical algorithm for men with combined Peyronie's disease and erectile dysfunction: functional and satisfaction outcomes. J Sex Med 2005;2:132-8.

12. Levine LA, Benson J, Hoover C. Inflatable penile prosthesis placement in men with Peyronie's disease and drug-resistant erectile dysfunction: A single-center study. J Sex Med 2010;7:3775-83.

13. Watson MJ, Shridharani A. Pump placement. Asvide 2019;6:084. Available online: http://www.asvide.com/ watch/33124

14. Wallen J, Beilan J, Emtage J, et al. 062 "Just the Tip" Closed Suction Drain Cultures after Implantation of Penile Prosthesis. J Sex Med 2016;13:S30.

15. Watson MJ, Shridharani A. Drain placement. Asvide 2019;6:085. Available online: http://www.asvide.com/ watch/33125

doi: 10.21037/jovs.2019.11.09

Cite this article as: Watson MJ, Shridharani A. Penoscrotal three-piece inflatable penile prosthesis placement: surgical technique. J Vis Surg 2020;6:26. 